\title{
Correction to: Balancing costs and confidence: volunteer-provided point observations, GPS telemetry and the genetic monitoring of Finland's wolves
}

\author{
Ilpo Kojola ${ }^{1} \cdot$ Samuli Heikkinen ${ }^{2} \cdot$ Katja Holmala $^{3}$
}

Published online: 23 May 2018

(C) Mammal Research Institute, Polish Academy of Sciences, Białowieża, Poland 2018

\section{Correction to: Mammal Research \\ https://doi.org/10.1007/s13364-018-0371-3}

The original version of this article contained errors and corrected as follows:

The year present in the fourth last sentence of the abstract previously reads as "...population estimate of $150-178$ wolves for early March 2016...", the correct year should be "2017". In the section heading "Known wolf mortality", the total recorded wolf dead should have been "54" instead of "58". Furthermore, under the Result section, originally reading "By taking into account the known mortality during our study period ( $\mathbf{5 8}$ wolves), we determined a minimum estimate of 208-236 wolves for early August 2016.", this should have read "By taking into account the known mortality during our study period ( 54 wolves), we determined a minimum estimate of 204-234 wolves for early August 2016." [bold text used to highlight problem area].

The remainder of the article remains unchanged.

The online version of the original article can be found at https://oi.org/ 10.1007/s13364-018-0371-3

Ilpo Kojola

Ilpo.Kojola@luke.fi

1 Natural Resources Institute (Luke), Box 16, FI-96301 Rovaniemi, Finland

2 Natural Resources Institute (Luke), University of Oulu, Paavo Havaksentie 3, FI-90014 Oulu, Finland

3 Natural Resources Institute (Luke), Latokartanonkaari 9, FI-00790 Helsinki, Finland 